\title{
ACONSELHAMENTO NA TESTAGEM RÁPIDA PARA DIAGNÓSTICO DE HIV: REFLEXÕES DA EXPERIÊNCIA EM UM CTA
}

\author{
Andressa Soares Azambuja1; Elizangela Freo Ruviaro²; Danieli Brum de \\ Souza $^{3}$; Julia Zancan Bresolin ${ }^{4}$; Félix Miguel Nascimento Guazina ${ }^{5}$
}

\section{RESUMO}

O presente trabalho tem como objetivo discutir a importância do aconselhamento no momento da testagem rápida para HIV, quais os desafios e possibilidades diante dessa prática em um Centro de Testagem e Aconselhamento (CTA). Constitui-se como uma pesquisa exploratória de base bibliográfica, utilizou-se desta metodologia para mapear o que há na literatura sobre aconselhamento na testagem rápida para HIV, através de pesquisas em sites de base científica e documentos do Ministério da Saúde. A grande oferta da testagem rápida para HIV no país oportuniza o fácil acesso ao diagnóstico, consistindo-se em estratégia de prevenção da disseminação das ISTs. O aconselhamento é um momento importante pois muitas vezes neste surgem dúvidas sobre tratamento e prevenção. Conclui-se que o aconselhamento é uma importante ferramenta para a educação em saúde de quem procura testagem devido a divulgação de importantes estratégias de prevenção além de contribuir para desmistificar os tabus em torno do HIV.

Palavras-chave: Diagnóstico; Teste rápido; Infecções Sexualmente Transmissíveis; Síndrome da Imunodeficiência Humana

Eixo Temático: Atenção Integral e Promoção à Saúde (AIPS)

\section{INTRODUÇÃO}

Este trabalho constitui-se como um relato de experiência a partir da atuação da psicóloga residente em um Serviço de Atendimento Especializado (SAE) e Centro de Testagem e Aconselhamento (CTA) localizado no interior do estado do Rio

\footnotetext{
1 Universidade Franciscana. Email: andressa.azambuja530@gmail.com

${ }^{2}$ Universidade Franciscana. Email: elizfreo@yahoo.com.br

${ }^{3}$ Prefeitura Municipal de Santa Maria - RS. Email: danielibrumpsico@gmail.com

${ }_{4}$ Prefeitura Municipal de Santa Maria - RS. Email: julia.bresolin92@gmail.com

${ }_{5}$ Universidade Franciscana. Email: guazia@gmail.com
} 
Grande do Sul, através da Residência Multiprofissional em Atenção Clínica Especializada com Ênfase em Infectologia e Neurologia da Universidade Franciscana (UFN). A inserção no campo de atuação ocorreu no mês de março de dois mil e vinte um, neste serviço especializado, que é referência para o tratamento de pessoas vivendo com o Vírus da Imunodeficiência Humana (HIV) e no tratamento das Hepatites Virais (B e C) no município onde está localizado. Além disso, o tratamento de lesões externas do Papiloma Vírus Humano (HPV) também é realizado no serviço, demais ISTs o tratamento é feito na atenção básica, salvo a Sífilis que a aplicação da medicação também pode ser feita neste, mas prioriza-se encaminhamento para rede básica.

Atualmente o serviço conta com uma equipe multiprofissional contendo quatro médicos infectologistas, um médico dermatologista, uma psicóloga, uma enfermeira, uma nutricionista, uma técnica de enfermagem, duas farmacêuticas, uma assistente social, uma auxiliar de laboratório, uma técnica administrativa, uma recepcionista e uma auxiliar de limpeza. Também compõem a equipe os quatro residentes multiprofissionais: dois psicólogos e duas enfermeiras. Além de três estagiários das áreas da enfermagem, psicologia e serviço social. Dentre as atividades realizadas temos a testagem rápida para sífilis, HIV e Hepatites $\mathrm{B}$ e $\mathrm{C}$, consultas médicas e com a nutricionista, coleta de exames de carga viral e de linfócitos T CD4+/CD8+, acolhimento de usuários encaminhados de outros serviços com exame positivo de HIV e Hepatites B e C para início de tratamento, atendimentos psicológicos, atendimentos com a profissional do serviço social, dentre outras atividades.

Neste trabalho será dado enfoque na testagem para a identificação de Infecções Sexualmente Transmissíveis (ISTs), especialmente o HIV devido a complexidade envolvida na sua assistência e prevenção. A testagem é realizada por meio de teste rápido sendo este "todos os testes cuja execução, leitura e interpretação do resultado são feitas em no máximo 30 minutos, sem a necessidade de estrutura laboratorial. A leitura dos resultados é feita a olho nu" (BRASIL, pag.13, 2010). Eles estão regulamentados pela Portaria N³4, de 28 de Julho de 2005 que 
permite o uso de testes rápidos para diagnóstico da infecção pelo HIV em situações especiais. Em seu artigo primeiro autoriza a utilização em serviços de saúde e maternidades a fim de ampliar o acesso ao diagnóstico da infecção pelo HIV (BRASIL, 2005).

Esta é uma atividade que a residente tem se aproximado cada vez mais no seu campo de atuação profissional, diante disso percebeu-se a importância de se discutir o aconselhamento durante a testagem para o HIV por tratar-se de uma doença infecciosa que ainda está em grande expansão no país e também devido ao desconhecimento da maioria da população sobre as estratégias de prevenção combinada para o HIV disponíveis no SUS, como por exemplo, a Profilaxia Pré-Exposição (PrEP) e a Profilaxia Pós-Exposição (PEP). Assim como a diferença entre HIV e Aids, os tabus em torno da Pessoa que Vive com HIV (PVHIV), manifestações da infecção, entre outras questões.

Ao serem realizados os atendimentos percebeu-se que o aconselhamento durante a execução da testagem rápida torna-se uma importante ferramenta para informar o usuário que vem ao serviço, bem como esclarecer dúvidas e orientar quanto a estratégias de prevenção das ISTs. É importante que esse momento seja acolhedor fazendo com que o usuário se sinta à vontade para falar quais motivos o levaram a buscar a testagem. Segundo Brasil (1999), entende-se por aconselhamento um modo de ajuda que busca apoiar as pessoas no enfrentamento de problemas específicos, imediatos e contextualizados no presente.

Diante do exposto, objetiva-se neste trabalho discutir a importância do aconselhamento no momento da testagem rápida para HIV, quais os desafios e possibilidades diante dessa prática.

\section{METODOLOGIA}

Este trabalho constitui-se como uma pesquisa exploratória de base bibliográfica. Segundo Minayo (2013), o caráter exploratório da pesquisa refere-se a 
definição e delimitação do objeto a ser estudado, desenvolvendo-o teórica e metodologicamente. Envolve também a escolha e a descrição dos instrumentos utilizados bem como os procedimentos para instrumentalizar o que será pesquisado.

Dessa forma, utilizou-se desta metodologia para mapear o que há na literatura sobre o aconselhamento na testagem rápida para HIV, através de pesquisas em sites de base científica como a Scientific Electronic Library Online (Scielo Brasil) e Literatura Latino-Americana e do Caribe em Ciências da Saúde (LILACS), bem como em documentos disponibilizados pelo Ministério da Saúde sobre ISTs, HIV/aids. Foram usados os seguintes descritores para a pesquisa dos artigos: aconselhamento/HIV; CTA/testes; HIV/testagem;

\section{REVISÃO DE LITERATURA}

O surgimento do vírus HIV/Aids no Brasil ocorreu em meados dos anos oitenta, atingindo uma parte específica da população. Os casos de AIDS (Síndrome da Imunodeficiência Adquirida) inicialmente ocorreram em homens homossexuais, usuários de drogas injetáveis, hemofílicos e pessoas que tinham passado por transfusão de sangue (SILVA \& SZAPIRO, 2015).

Diante disso a história da epidemia no país pode ser dividida em três fases: a primeira relaciona-se a um olhar voltado ao infectado, o que acabou impedindo a adoção de ações mais amplas no campo da saúde, caracterizando-se pela transmissão principalmente em homens que fazem sexo com homens, e por um nível de escolaridade alto entre as pessoas infectadas, estabelecendo um conceito de "grupo de risco"; A segunda fase ampliou o olhar sobre a exposição ao vírus devido também a transmissão em usuários de drogas injetáveis e por uma maior disseminação entre as pessoas heterossexuais, passando a noção de um "comportamento de risco"; e a terceira fase caracteriza-se pela suscetibilidade das pessoas ao vírus, havendo uma maior disseminação entre os heterossexuais, principalmente mulheres, um aumento significativo entre pessoas de baixa escolaridade e também em municípios de médio e pequeno porte, causando a 
chamada interiorização, diante desses fatos surge o conceito de "vulnerabilidade" ao vírus (BRASIL, 1999).

Frente a esses fatos houve a necessidade de estabelecer uma política pública para ampliar as ações de prevenção, assistência e fortalecimento institucional, exigindo um esforço maior e envolvimento dos diversos setores governamentais e não-governamentais no enfrentamento à epidemia (BRASIL, 1999). São grandes os desafios nesse enfrentamento e para isso o governo federal, através do Ministério da Saúde, criou a Política Nacional de DST/Aids, hoje conhecida como Política Nacional de enfrentamento ao HIV/Aids, Hepatites Virais e Infecções Sexualmente Transmissíveis.

Várias são as ações para esse enfrentamento, dentre elas estão: a criação dos Centro de Testagem e Aconselhamento (CTA). Esses centros foram implantados no final da década de 80 , inicialmente chamados de Centros de Orientação e Apoio Sorológico (COAS), eram considerados uma modalidade alternativa de serviços de saúde, que devia oferecer sorologia anti-HIV gratuita, confidencial e anônima, além de prover educação e aconselhamento para os indivíduos com risco de infecção pelo HIV. Compostos de equipes próprias e multiprofissionais, os CTA, nesse primeiro momento, eram destinados a segmentos populacionais prioritários sendo estes identificados como de maior risco para a infecção, como os homossexuais, profissionais do sexo e usuários de drogas injetáveis. (BRASIL, 2010).

Os principais objetivos desse tipo de serviço era expandir o acesso das pessoas ao diagnóstico de HIV e de suas parcerias, contribuir na redução de risco de transmissão do HIV e estimular a adoção de práticas sexuais seguras, absorver a demanda de testes sorológicos em bancos de sangue, informar sobre prevenção e encaminhar pessoas com diagnóstico de HIV positivo para serviços de referência, auxiliando os usuários no processo de adesão ao tratamento (BRASIL, 1999).

Devido a mudança no perfil epidemiológico da epidemia em meados dos anos noventa com o crescimento do número de casos novos entre heterossexuais, mulheres, população de baixa renda e sua interiorização, precisou-se ampliar a 
oferta de ações para enfrentar essa mudança. Os CTA então tornam-se referência no acesso universal à testagem e aconselhamento em DST/Aids, expandindo a oferta de teste e de orientações de prevenção do HIV e outras ISTs, destinadas à população em geral e a segmentos populacionais ditos de maior vulnerabilidade (BRASIL, 2010). Atualmente, os CTA e os demais serviços do Sistema Único de Saúde (SUS) são considerados serviços estratégicos na promoção da equidade de acesso ao diagnóstico e ao aconselhamento relacionados ao HIV/Aids, bem como ao diagnóstico de Sífilis e Hepatites Virais no país (BRASIL, 2010).

\section{RESULTADOS E DISCUSSÃO}

Segundo a UNAIDS (2021) foram registrados no mundo 1,5 milhões de pessoas infectadas pelo vírus HIV em 2020. Dados do Boletim Epidemiológico HIV/aids do Departamento de Doenças de Condições Crônicas e Infecções Sexualmente Transmissíveis, da Secretaria de Vigilância em Saúde, do Ministério da Saúde (DCCI/SVS/MS), que é publicado anualmente, aponta que de 2007 até junho de 2019, foram notificados no Sistema de Informações de Agravos de Notificação (SINAN) 300.496 casos de infecção pelo HIV no Brasil (BRASIL, 2019). Segundo Brasil (2018) o HIV possui hoje status de doença crônica devido a doenças cardiovasculares, hipertensão e diabetes se tornaram mais prevalentes entre as PVHIV.

Diante disso, a grande oferta da testagem rápida para HIV no país oportuniza o fácil acesso ao diagnóstico, consistindo-se em estratégia de prevenção da disseminação das ISTs. A oferta da testagem para o HIV e outras IST especialmente à população jovem, permite diagnosticar precocemente a infecção, fazendo com que essas pessoas tenham acesso aos benefícios do tratamento, melhorando o seu prognóstico e qualidade de vida e de suas parcerias (BRASIL, 2018). Por meio dos testes rápidos que podem ser feitos através de fluido oral, soro, plasma ou sangue total, este último permite o uso de amostras obtidas por punção digital (BRASIL, 2017). Os testes utilizados no CTA são os que usam amostra de sangue por punção 
digital através da coleta de uma gota de sangue com pipeta, e o de fluido oral que é utilizado como teste confirmatório caso o primeiro teste para HIV seja positivo.

No serviço onde a psicóloga residente atua a procura por este tipo de teste é bastante intensa. O perfil de quem procura a testagem é diverso, desde pessoas que tiveram uma exposição de risco recente até aquelas que já têm a testagem como rotina. Podemos destacar alguns motivos: mulheres/homens com companheiros (as) soropositivos (as), acidente com perfurocortante, relação sexual sem ou onde houve rompimento do preservativo, pessoas que nunca realizaram testagem e desejam fazer pela primeira vez.

O CTA atende por demanda espontânea os usuários que desejam testar-se, ao chegar são encaminhados a um profissional psicólogo ou enfermeiro para a realização dos testes. São feitas orientações pré teste onde se explica quais as ISTs que serão testadas bem como qual o precedimento que vai ser utilizado na realização da testagem. Segundo Brasil (2017) a oferta da testagem (pré teste) pode ser acompanhada por orientações sendo um momento de informar as pessoas sobre o processo de realização da testagem e seus significados, de acordo com as necessidades e o contexto de cada usuário(a), tendo o cuidado para que essas orientações não tornem o processo prescritivo, burocrático ou rígido. Deve-se informar o possível resultado dos testes, verificar imunização para Hepatite B e HPV (se for o caso) e esclarecer eventuais dúvidas.

A fim de não transformar esse momento em algo mecânico, a residente no início da testagem explica os procedimentos de realização do teste e quais são as ISTs testadas. Enquanto se espera o resultado utiliza-se este momento para as orientações pós teste e o aconselhamento. Este último consiste em uma tecnologia de cuidado que se relaciona principalmente ao gerenciamento de risco no contexto das IST, do HIV/aids e das hepatites virais, baseado em intervenções comportamentais, biomédicas e estruturais. Sua oferta deve ser flexível sem ser obrigatória, permitindo assim que cada indivíduo saiba dessa possibilidade e possa decidir se deseja ou não se submeter a essa intervenção. $O$ aconselhamento tem 
caráter ágil, dinâmico e focado (BRASIL, 2017).

Diante disso são feitas orientações quanto aos testes realizados, explicando as características de cada IST testada e formas de tratamento e prevenção. Em relação ao HIV apresenta-se as estratégias de prevenção combinada através da apresentação da Mandala da Prevenção Combinada (desenho onde contém todas as estratégias disponíveis para prevenção ao HIV). Informa-se também a disponibilidade da PEP e da PrEP no município, a fim de divulgar para população sobre essas duas medidas de prevenção disponíveis ao qual muitas pessoas desconhecem a existência, o que são e para que servem. Além da importância do uso do preservativo, da testagem rápida regular, sobre período de janela imunológica, identificar e tratar as demais ISTs, etc.

De acordo com Araújo et. al. (2018) o aconselhamento é uma etapa fundamental no processo de testagem. Sendo necessário o profissional prestar um suporte emocional adequado, buscando estabelecer um vínculo de confiança, desse modo o usuário se sentirá mais seguro em explicitar suas práticas de risco, oportunizando ao profissional realizar intervenções mais efetivas. Ademais, nos casos de diagnóstico positivo para a infecção por HIV, cabe ao profissional oferecer ao indivíduo o apoio emocional para lidar com o resultado e sua nova nova condição.

Este é um momento onde muitas vezes surgem dúvidas sobre tratamento e prevenção, percebe-se uma grande preocupação e medo de contágio da infecção pelo HIV em relação às outras ISTs testadas. Nota-se uma prevalência de questões relacionadas ao tabu que ainda existe sobre o vírus HIV, muitos ainda têm em mente que o tratamento é realizado com os "coquetéis", que pessoas que são soropositivas estão condenadas à morte, que não se pode compartilhar objetos com a pessoa soropositiva, entre outras questões. Segundo Araújo et. al. (2018) ainda é muito presente na população o estigma associado à doença, existindo a necessidade de ações de educação em saúde relacionadas à infecção por HIV/ aids. De acordo com Silva, Silva \& Ferreira (2019) o processo do aconselhamento em HIV/Aids implica 
lidar diretamente com situações distintas, que muitas vezes são distantes dos nossos valores e estilos de vida.

Vale ressaltar que diante da complexidade que permeia a questão da testagem rápida é imprescindível ter um conhecimento e estar atento às atualizações dos Protocolos Clínicos e Diretrizes Terapêuticas (PCDTs) das ISTs testadas, pois neles contém informações sobre cada uma delas em relação ao tratamento e prevenção, medicamentos utilizados bem como as condutas a serem adotadas (BRASIL, 2017). Fazendo com que as informações passadas ao usuário no aconselhamento sejam baseadas em conhecimentos científicos.

\section{CONCLUSÃO}

Diante do exposto conclui-se que o aconselhamento é uma importante ferramenta para a educação em saúde das pessoas que procuram a testagem rápida, devido a divulgação de importantes estratégias de prevenção, muitas vezes desconhecidas da maioria da população, com a finalidade de que mais pessoas tenham acesso a elas. Além da transmissão dessas informações é preciso estar atento às demandas trazidas por estes sujeitos, suas dúvidas e questionamentos, ter uma escuta atenta é fundamental, principalmente no que diz respeito ao acolhimento destes usuários em sua singularidade. Sendo importante não transformar esse momento em mera transmissão de informações mas em um espaço de troca.

Um dos desafios frente ao aconselhamento relaciona-se ao fato de proporcionar ao sujeito um espaço acolhedor onde ele se sinta à vontade para esclarecer suas dúvidas e expor os reais motivos para buscarem a testagem. $\mathrm{Na}$ minha experiência atendi pessoas que após o aconselhamento, com a escuta às demandas delas, revelaram a sua situação de exposição ao risco dizendo se sentir mais tranquilas para fazer isso após essa conversa. É importante fazer perguntas a fim de investigar como foi essa exposição sem medo de ser invasivo para melhor compreender a situação.

O trabalho no CTA realizando a testagem rápida e o aconselhamento 
proporciona ao profissional que executa os testes rápidos uma importante ferramenta para a divulgação de informações e quebra de estigmas sobre o HIV. Desmistificar os tabus em torno do viver com HIV e sobre o tratamento e prevenção ajuda na quebra do preconceito a essas pessoas. Informar que não existem mais grupos de risco mas sim que qualquer pessoa que tenha uma vida sexual ativa está vulnerável ao vírus é fundamental.

Vale ressaltar também a importância tanto da prevenção quanto do diagnóstico precoce para se evitar a disseminação do vírus HIV, quanto mais cedo o usuário saber sobre sua sorologia mais cedo terá acesso ao tratamento ficando indetectável (intransmissível) e assim evitando a transmissão às suas parcerias, utilizando além da Terapia Antirretroviral (TARV) também as demais estratégias da prevenção combinada.

\section{REFERÊNCIAS}

ARAÚJO, Willamis José et al. Percepção de enfermeiros executores de teste rápido em Unidades Básicas de Saúde. Rev. Bras. Enferm. , v. 71, supl. 1, pág. 631-636, 2018.

Disponível

em: $<$ <ttp://www.revenf.bvs.br/scielo.php?script=sci_arttext\&pid=S0034-71672018000300 $631 \& \operatorname{lng}=$ pt\&nrm=iso $>$.

BRASIL. HIV: Estratégias para utilização de testes rápidos no Brasil. Brasília: Ministério da Saúde, Departamento de DST, Aids e Hepatites Virais. 98p., 2010.

Boletim Epidemiológico. Secretaria de Vigilância em Saúde | Ministério da Saúde Número Especial | Dez. 2019. Disponível em: http://www.aids.gov.br/pt-br/pub/2019/boletim-epidemiologico-de-hivaids-2019 
EDUGAÇÃO, SAÚDE

ETECNOLOGIA

26 A 28 DE OUTUBRO DE 2021

- Diretrizes dos Centros de Testagem e Aconselhamento - CTA:

manual./Coordenação Nacional de DST e Aids. _ Brasília: Ministério da Saúde, 32p. 1999.

- Ministério da Saúde. Secretaria de Vigilância em Saúde. Departamento de DST, Aids e Hepatites Virais. Diretrizes para Organização e Funcionamento dos CTA do Brasil. Brasília: Ministério da Saúde, 2010.

- Diretrizes para organização do CTA no âmbito da Prevenção

Combinada e nas Redes de Atenção à Saúde. Ministério da

Saúde, Secretaria de Vigilância em Saúde, Departamento de Vigilância, Prevenção e Controle das Infecções Sexualmente Transmissíveis, do HIVIAids e das Hepatites Virais. - Brasília : Ministério da Saúde, 2017.

Política Nacional de DST/aids: princípios e diretrizes / Coordenação

Nacional de DST e Aids. 1. ed. _Brasília: Ministério da Saúde, 1999. p. 90

PORTARIA No 34, DE 28 DE JULHO DE 2005. Regulamenta o uso de testes rápidos para diagnóstico da infecção pelo HIV em situações especiais. Disponível:https://bvsms.saude.gov.br/bvs/saudelegis/svs/2005/prt0034 28072005 $\underline{. h \mathrm{tml}}$

- Brasil. Protocolo Clínico e Diretrizes Terapêuticas para Manejo da Infecção pelo HIV em Adultos. Secretaria de Vigilância em Saúde, Departamento de Vigilância, Prevenção e Controle das Infecções Sexualmente Transmissíveis, do HIVIAids e das Hepatites Virais. - Brasília : Ministério da Saúde, 2018.

LIMA, Paula Barreto Silva Xenofonte Costa et al . Percepção dos profissionais de saúde e dos usuários sobre o aconselhamento no teste rápido para HIV. Esc. Anna Nery, , v. 24, n. 2, e20190171, 2020. Disponível em: 
$<$ http://www.revenf.bvs.br/scielo.php?script=sci_arttext\&pid=S1414-81452020000200 218\&lng=pt\&nrm=iso $>$.

MINAYO, Maria Cecília de Souza. Capítulo II: O projeto de pesquisa como exercício científico e artesanato intelectual. In:_Pesquisa Social: Teoria, Método e Criatividade. Suely Ferreira Deslandes e Romeu Gomes, Maria Cecília Minayo (org.). - Petrópolis, RJ: Vozes, 2013. 34ª edição. Edição digital.

SILVA, Tamara Queiroz Costa. SZAPIRO, Ana Maria. Mulheres heterossexuais em relacionamento estável: limites do aconselhamento em DST/HIVIAIDS. Rev. Subj. [online]. 2015, vol.15, n.3 , pp. 350-361 Disponível em:

http://pepsic.bvsalud.org/scielo.php?script=sci abstract\&pid=S2359-0769201500030 $\underline{0004}$

SILVA, Yugo Torquato da. SILVA, Luciano Bairros da. FERREIRA, Sônia Maria Soares. Práticas de aconselhamento em infecções sexualmente transmissíveis/aids: perspectiva das profissionais de saúde. Rev Bras Enferm;72(5):1200-7, 2019. Disponível em: scielo.br/j/reben/a/zsDsDDxCvLGF9cHybzTwDdc/?format=pdf\&lang=pt 